\title{
La traction animale et son environnement au Burkina Faso, au Cameroun et au Sénégal
}

\author{
M. Havard ${ }^{1}$ A. Traoré ${ }^{2}$ A. Njoya ${ }^{3}$ A. Fall ${ }^{4}$
}

\section{Mots-clés}

Energie animale - Culture attelée - Privatisation - Matériel Entretien - Environnement - Burkina Faso - Cameroun - Sénégal.

\begin{abstract}
Résumé
Au Burkina Faso, au Cameroun et au Sénégal, la traction animale continue sa progression dans un contexte de désengagement des Etats des filières de cultures industrielles et de libéralisation du secteur agricole. Le taux d'équipement des exploitations agricoles est stable et supérieur à 95 p. 100 depuis 25 ans dans le bassin arachidier sénégalais. Inférieur à 35 p. 100, il croît régulièrement grâce à l'action de la société cotonnière au Nord-Cameroun, tandis qu'il progresse par à coups en fonction des programmes ponctuels d'appui à l'agriculture dans la Tapoa au Burkina Faso. La privatisation des services d'appui à la traction animale assurés par des structures de l'Etat est effective au Sénégal et en cours dans les deux autres situations. Cette privatisation montre que l'approvisionnement, et l'entretien des animaux et des agroéquipements sont assurés tant bien que mal par les artisans du fer et les commerçants. En revanche, les nouveaux prestataires des services (financiers, appui/conseil, actes vétérinaires) ont des difficultés à adapter leur offre à la demande. Dans les zones les plus sèches, les conditions pluviométriques nécessitent de semer rapidement et d'effectuer précocement l'entretien des cultures. Cela explique la présence des semoirs et des houes dans le bassin arachidier sénégalais, le semis manuel sans travail du sol sur les céréales au Nord-Cameroun. Dans les zones plus humides (Tapoa au Burkina et partie méridionale du Nord-Cameroun), la période favorable à l'implantation des cultures est plus longue. Les pluies précoces favorisent la levée de la végétation qui est enfouie avant les semis par le labour aux bœufs. Cette diversité d'utilisation et d'environnement de la traction animale nécessite que le développement et la recherche adaptent leurs programmes aux différents contextes.
\end{abstract}

\section{INTRODUCTION}

En Afrique subsaharienne, l'utilisation de la traction animale est ancienne et répandue sur les plateaux en Ethiopie. Elle reste marginale dans les régions arides, où la faible pluviométrie annuelle (moins de $400 \mathrm{~mm}$ ) limite fortement l'agriculture, et dans les régions humides (plus de $1200 \mathrm{~mm}$ ) et boisées à cause des maladies rendant difficile l'élevage d'animaux de trait. Elle continue à progresser

\footnotetext{
1. Cirad, département Tera, 73 rue Jean-François Breton,

34398 Montpellier Cedex 5, France

E-mail : michel.havard@cirad.fr

2. Association Tin Tua, BP 167, Fada N'gourma, Burkina Faso

E-mail : desire_traore@hotmail.com, tintua2@fasonet.bf

3. Irad, BP 2067, Yaoundé, Cameroun

E-mail : njoya_aboubakar@yahoo.fr

4. Isra, BP 240, Saint-Louis, Sénégal

E-mail : fallalio@ refer.sn
}

dans les régions semi-arides (400 à $800 \mathrm{~mm}$ ) et subhumides (800 à $1200 \mathrm{~mm}$ ) où l'agriculture et l'élevage d'animaux aptes au travail (bovins, équins et asins) sont répandus (12). Depuis 1960, dans les régions francophones d'Afrique subsaharienne, les effectifs sont passés de quelques milliers à plus de deux millions d'animaux de trait et d'unités de matériels agricoles.

Ces cinquante dernières années, les sociétés de développement des cultures industrielles ont eu une action déterminante dans la diffusion de la traction animale en fournissant aux producteurs les services nécessaires pour faciliter l'adoption de la technique (crédit, conseil, suivi vétérinaire...). Avec la libéralisation de l'économie, ces services ont été totalement ou partiellement démantelés et leurs moyens d'intervention fortement réduits. Aujourd'hui, les producteurs doivent de plus en plus compter sur des prestataires de services locaux, tels que les privés, les organisations paysannes (OP) ou les organisations non-gouvernementales (ONG). Les OP étant encore peu impliquées dans ces activités, il en résulte 
une réduction des crédits de campagne et d'équipement, et la suppression des bonifications sur les taux d'intérêt. Cette situation, combinée à une hausse des prix du matériel, limite les possibilités d'équipement des agriculteurs.

Ces vingt dernières années, la combinaison de l'accroissement de la population rurale avec les fortes sécheresses (1970-73, 1983-85) et la persistance des aléas pluviométriques ont augmenté les flux d'agriculteurs et d'éleveurs des régions peuplées ( $\left.>80 \mathrm{hab} . / \mathrm{km}^{2}\right)$ vers celles moins peuplées. Ceci se traduit par une augmentation de la pression foncière. Des dégradations du milieu naturel sont constatées : réduction du temps de friche, disparition des ligneux, accentuation des phénomènes érosifs et diminution de la fertilité des sols. L'augmentation des rendements, voire même leur maintien semblent difficiles à assurer. La traction animale a parfois contribué à accentuer ces dégradations en facilitant l'accroissement des superficies cultivées sur des terrains fragiles et aux potentialités agricoles plus faibles.

L'évolution des conditions agroécologiques dans des contextes socio-économiques diversifiés amène des questions sur la traction animale : comment s'est-elle diffusée ? pour quelles opérations agricoles et quels travaux est-elle utilisée ?

Cette étude, réalisée au Burkina Faso, au Cameroun et au Sénégal, analyse les particularités des évolutions de l'environnement sociotechnique de la traction animale, puis discute les conditions d'utilisation de la traction animale dans les systèmes de production des zones étudiées.

\section{MATERIEL ET METHODES}

Pour mener une analyse comparative, trois situations contrastées d'utilisation de la traction animale (bassin arachidier au Sénégal, bassin cotonnier au Nord-Cameroun, province de la Tapoa au Burkina Faso) ont été choisies sur la base des critères suivants : taux d'exploitations équipées, état d'avancement du processus de désengagement de l'Etat, types d'utilisation de la traction animale (figure 1). L'analyse de l'évolution de l'environnement de la traction animale a été réalisée à partir d'études bibliographiques. Les discussions sur les systèmes de production s'appuient sur des enquêtes $(3,5,6,13)$.

Le bassin arachidier sénégalais comprend deux zones principales : le Centre Nord (régions de Louga, Thiès, Diourbel et nord de la région de Fatick), fortement peuplé (plus de 80 hab. $/ \mathrm{km}^{2}$ ), connaissant de fortes contraintes pluviométriques et une baisse notable de la fertilité du sol, et la zone Sud (région de Kaolack et sud de la région de Fatick), disposant d'une pluviométrie plus favorable (> $600 \mathrm{~mm} / \mathrm{an}$ ) et de plus de ressources en terres et en parcours du fait d'un moindre peuplement (20 à 60 hab. $/ \mathrm{km}^{2}$ ). Les systèmes de culture sont basés sur le mil et le sorgho pour les vivriers, et l'arachide industrielle, cultivés dans des rotations excluant la jachère. L'arachide reste un élément central des systèmes de production agricole pour les revenus monétaires et pour l'alimentation des animaux (fanes). Les agriculteurs diversifient leurs activités avec l'embouche, le transport attelé hippomobile et les migrations de travail depuis de nombreuses années $(2,15)$.

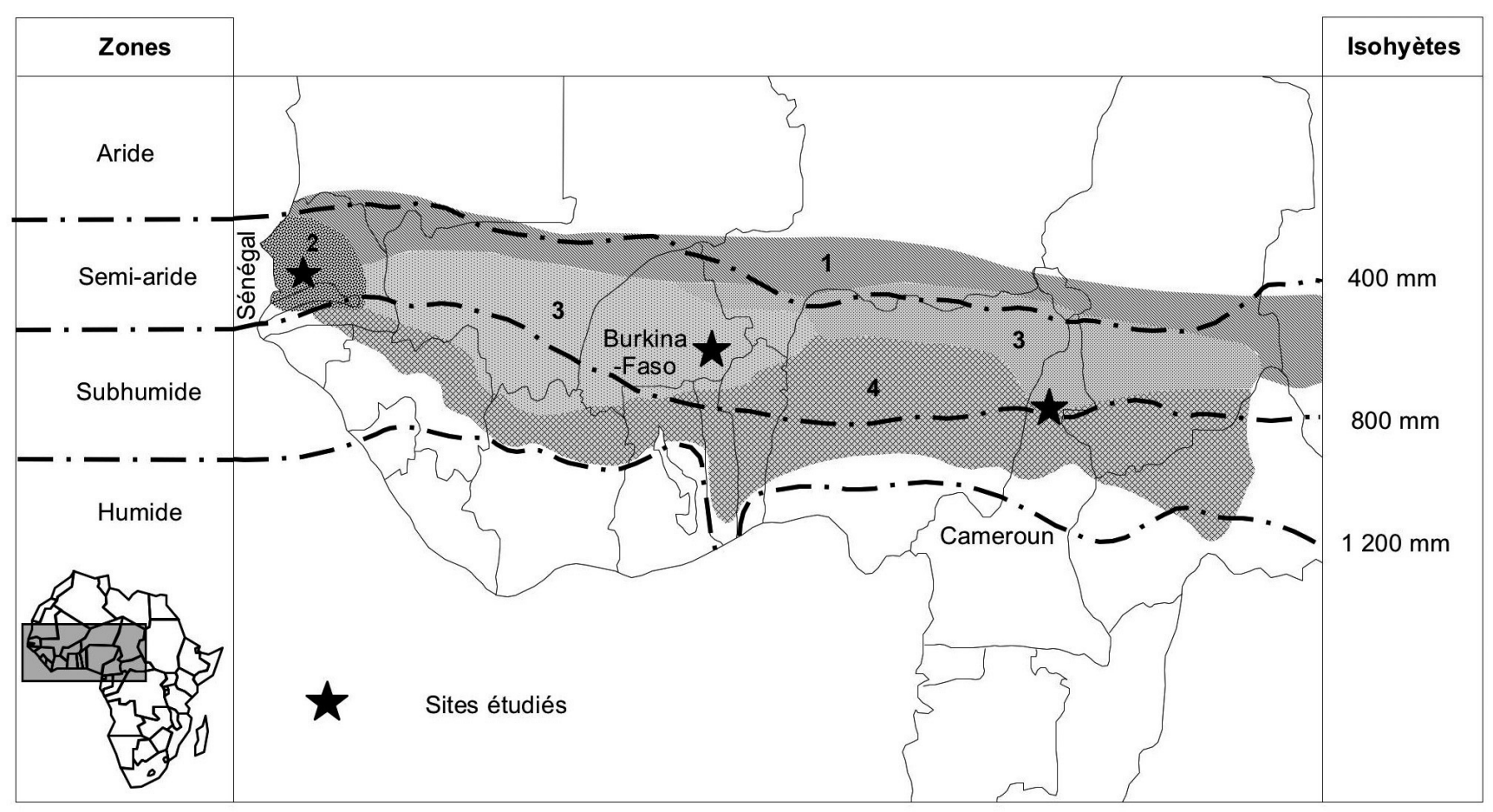

1. Energie animale (portage et transport)

Taux d'exploitations équipées en traction animale

2. Tractions équine et asine (semis et sarclo-binages)

3. Traction bovine (travail du sol et entretien des cultures) et asine (transport)

4. Traction bovine (travail du sol)

Figure 1 : localisation des sites d'étude et représentation des modes d'utilisation de la traction animale en Afrique subsaharienne. Source : Havard et coll., 1998, Agric. Mech. Asia, Afr. Latin Am. 
L'Institut sénégalais de recherches agricoles (Isra) a choisi le premier village (Yéri Gueye) au nord du bassin arachidier en zone plus sèche et le second (Keur Bakary) en zone plus humide au sud du bassin arachidier (figure 2).

Le bassin cotonnier du Nord-Cameroun comprend deux zones : l'Extrême-Nord, peu arrosée (600-800 $\mathrm{mm}$ de pluviométrie annuelle), densément peuplée ( $80 \mathrm{hab} . / \mathrm{km}^{2}$ en moyenne), région historique de la culture cotonnière, et la province du Nord, peu peuplée (10 à 50 hab. $/ \mathrm{km}^{2}$ ) et mieux arrosée (900-1 $200 \mathrm{~mm}$ ). La pluviométrie limitante à l'Extrême-Nord a conduit à des systèmes adaptés aux risques climatiques élevés, avec un nombre d'espèces limité, principalement les sorghos pluviaux (résistants à la sécheresse), le coton et le sorgho de saison sèche ou muskwari. Au Nord, la pluviosité plus élevée (> $1000 \mathrm{~mm} / \mathrm{an}$ ) et des sols plus favorables ont permis une gamme de cultures plus large, avec notamment le maïs et l'arachide. Cette province est le point de chute des migrations venant de l'Extrême-Nord, car elle dispose d'importantes possibilités d'extension des superficies cultivées.

L'Institut de recherches agricoles pour le développement (Irad) a choisi les cinq terroirs du Pôle de recherche appliquée au développement des savanes d'Afrique centrale (Prasac) : Balaza Domayo, Gadas et Mowo dans la province de l'Extrême-Nord, et Fignolé et Mafa Kilda dans la province du Nord (figure 3).

Au Burkina Faso, la pluviométrie annuelle de la province de la Tapoa est comprise entre $600 \mathrm{~mm}$ au nord et $800-900 \mathrm{~mm}$ au sud. La densité de population est faible, entre 10 et $18 \mathrm{hab} . / \mathrm{km}^{2}$. Au nord, les systèmes de culture sont basés sur le petit mil, le sorgho blanc et l'arachide. Au sud, les cultures sont plus diversifiées avec le coton, le maïs et le sorgho. Le taux d'équipement des exploitations est faible (environ 12 p. 100, contre 22 p. 100 en moyenne sur l'ensemble du pays). L'équipement se limite souvent à une charrue asine (CH6) ou bovine (CH9), et parfois à un tombereau asin (6 p. 100 des exploitations équipées). Environ 8 p. 100 des exploitations possèdent un attelage asin et $6 \mathrm{p} .100$ une paire de bovins (13, 21). Bovins et ânes sont utilisés pour le labour et l'entretien des cultures (buttage essentiellement), mais aussi pour le transport.

L'association Tin Tua ${ }^{1}$ a choisi deux diéma (unions de groupements) de sa zone d'intervention (figure 4). Sur Botou, située au nord de la province en zone plus sèche, sans culture de coton, la traction animale est mal connue et peu pratiquée. Sur Boaguidigou, au sud de la province, la traction animale est mieux connue et la Société des fibres et textiles (Sofitex) vient de relancer la culture du coton. Tin Tua a financé des matériels agricoles sur sa zone d'intervention (13)

\section{RESULTATS ET DISCUSSION}

\section{Des évolutions majeures de l'environnement socio-technique de la traction animale}

\section{Bassin arachidier du Sénégal}

De 1960 à 1980, dans le cadre du Programme agricole (PA) $(2,15)$, le gouvernement sénégalais a affecté d'importants moyens pour équiper les exploitations agricoles et leur faciliter l'accès aux engrais minéraux et aux semences sélectionnées en vue d'accrồtre les surfaces et les rendements d'arachide. Grâce à ces mesures, l'arachide a occupé jusqu'à la fin des années 1990 environ 50 p. 100 de l'assolement régional. Plus de 80 p. 100 des agroéquipements utilisés aujourd'hui ont été financés et distribués pendant cette période. Pour leur fabrication, le PA s'est appuyé sur une industrie locale, la Société Industrielle sénégalaise de constructions mécaniques et de matériels agricoles (Siscoma). Celleci a fait faillite en 1980 quand le système de financement du PA s'est trouvé paralysé par le non-remboursement des crédits et les retards de paiement des coopératives. Les institutions mises en place se sont avérées incapables de recouvrir les créances (10). Depuis, les paysans sont laissés à eux-mêmes pour l'acquisition, le renouvellement et l'entretien de leurs matériels agricoles. Mais le niveau d'équipement atteint s'est maintenu grâce au réseau des artisans du fer $(5,16)$ qui ont pris progressivement le relais de l'industrie locale, surtout pour l'entretien des agroéquipements mais beaucoup moins pour leur fabrication. Ces artisans ont aussi été sollicités par les paysans pour adapter certains outils (lames souleveuses, mini-houe Sine). Comme ils utilisent des matériaux de récupération généralement de qualité inférieure à ceux utilisés par les industries, leurs produits (pièces et matériels) sont souvent de

\footnotetext{
${ }^{1}$ Les objectifs de cette ONG, créée en 1989, visent un développement humain harmonieux et durable, par la lutte contre l'ignorance et la pauvreté, et la sauvegarde des ressources naturelles. C'est une fédération de 14 diéma qui rassemblent 426 groupements Tin Tua disséminés dans le Goulmou (13).
}

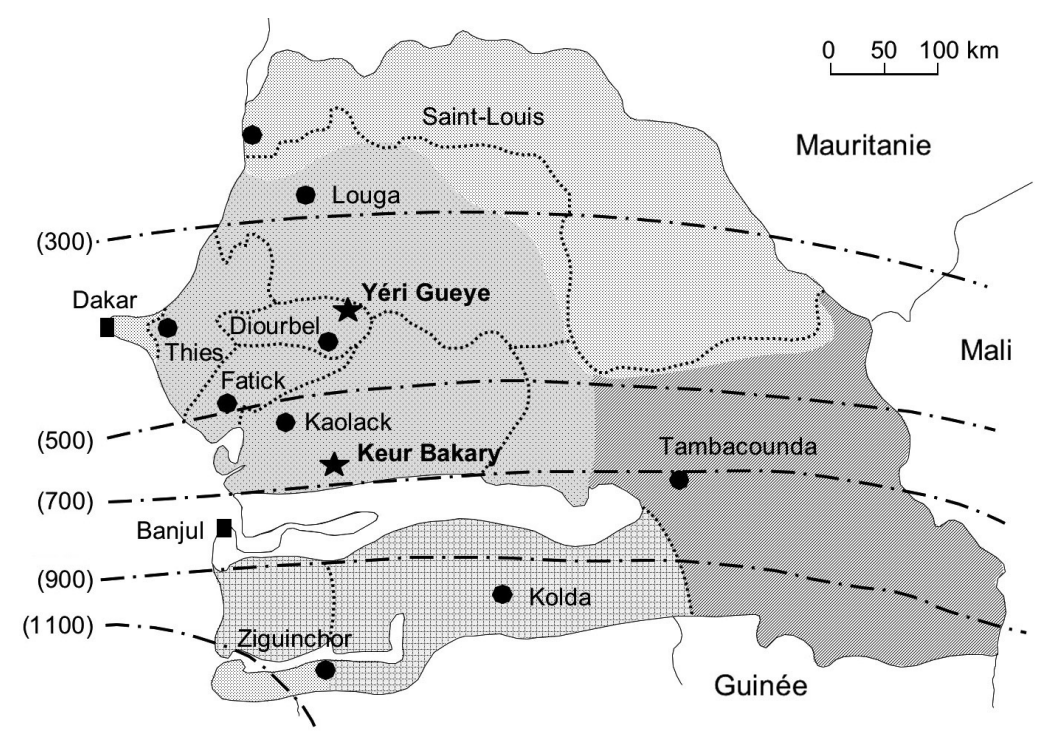

Régions de Saint-Louis et Dakar (transport), département d'Oussouye (pas de traction animale) Bassin arachidier (houes, semoirs, souleveuses, charrettes, chevaux, ânes)

Sénégal oriental (butteurs, charrues, bovins)

Casamance (butteurs, charrues, bovins)

(1 100) Isohyètes 1968/1985 en mm

Limites des régions administratives

$\star \quad$ Sites étudiés

Figure 2 : localisation des villages de Yéri Gueye et de Keur Bakary au Sénégal. 


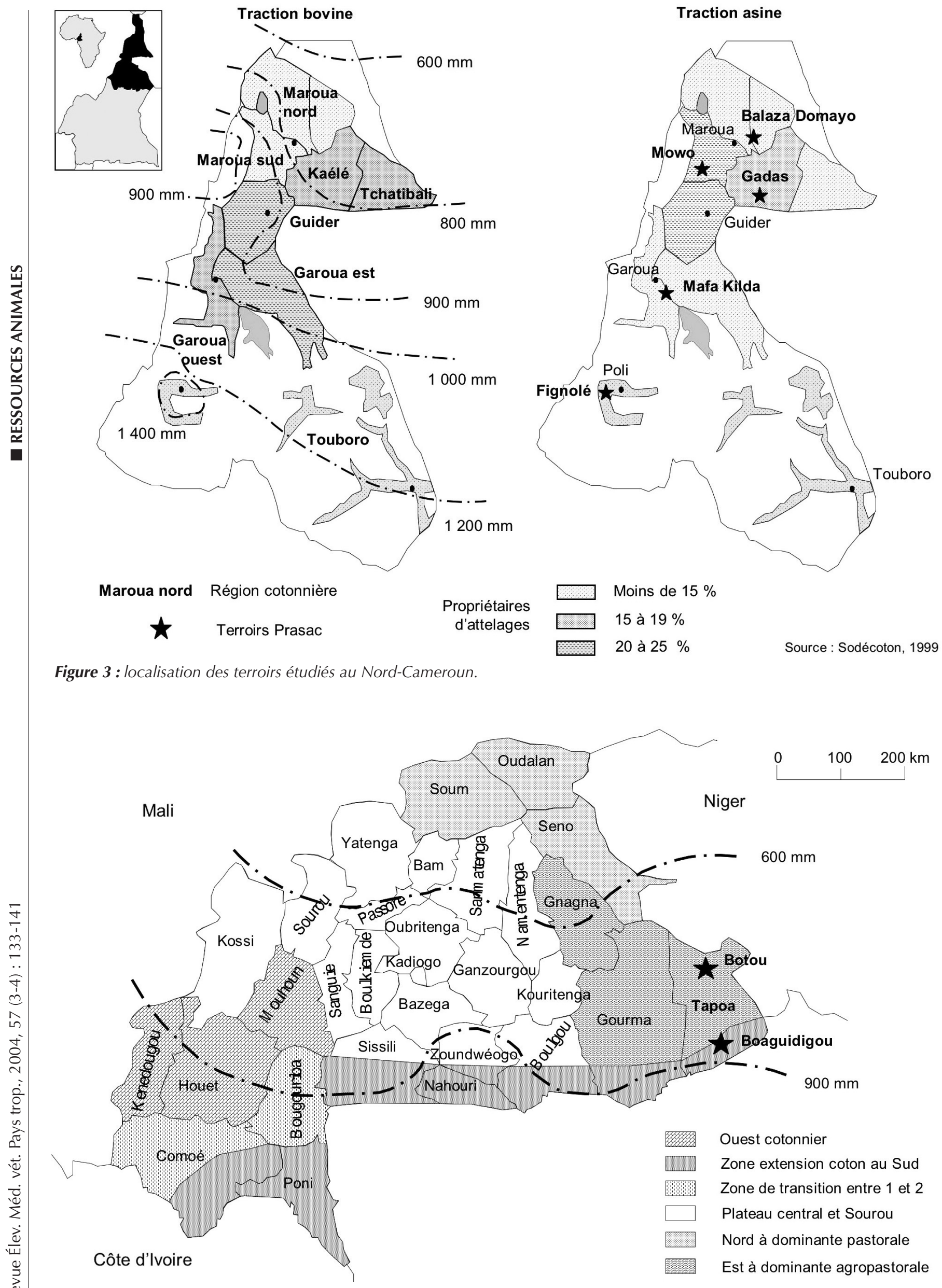

Figure 4 : localisation des sites de Botou et Boaguidigou à l'est du Burkina Faso. 
qualité moindre. Mais, ils ont l'avantage d'être moins chers que les produits industriels. En revanche, le parc de semoirs SuperEco est en mauvais état, malgré les efforts des artisans pour les entretenir, car ils n'arrivent pas à reproduire à moindre coût le système de distribution (14).

En 1980, la quasi-totalité des exploitations agricoles du bassin arachidier disposait d'au moins une unité de traction (un cheval ou un âne, parfois une paire de bœufs), d'un semoir (SuperEco), d'une houe (occidentale ou Sine), d'une lame souleveuse et bien souvent d'une charrette. Le choix des paysans pour une culture attelée « légère » s'est opéré rapidement et n'a jamais été remis en cause par la suite, malgré les opérations de vulgarisation de thèmes « lourds » (traction bovine, labour à la charrue et polyculteur). Pour l'ensemble des régions de Fatick et de Kaolack on comptait, en 1985, 105000 chevaux et ânes et 25000 paires de bovins dont 5000 paires de vaches de trait (10).

\section{Bassin cotonnier du Nord-Cameroun}

La traction animale a connu un développement lent et irrégulier jusque dans les années 1980. Depuis, le rythme d'équipement s'est nettement accéléré (18). De 1930 à 1950, l'administration coloniale hésitant entre le développement de l'arachide et celui du coton tenta, sans succès, d'initier les agriculteurs à la culture attelée. De 1950 à 1973, suite à des essais techniques divers, les agronomes de la Compagnie française des textiles (Cfdt) optèrent pour le labour à la charrue tractée par une paire de zébus, afin de favoriser l'extension des surfaces de coton. La traction animale a progressé lentement et irrégulièrement, au rythme des opérations de crédits, mais son utilisation resta limitée au labour du coton. Les sécheresses de 1970-73 ont affecté durement la culture cotonnière et la traction animale a reculé. De 1974 à 1993, la Société de développement du coton (Sodécoton, organisme d'Etat en charge du secteur, créée en 1974) a surmonté cette première crise cotonnière par une série de mesures de relance et d'intensification de la production. En matière de traction animale, la Sodécoton est restée sur les choix techniques d'avant 1973, restreignant l'offre de matériels pour faciliter la maintenance. Elle assurait tous les services d'appui à la traction animale, y compris la santé des animaux. A partir de 1978 (17), l'essor de la technique fut important. La seconde crise cotonnière (1989-93) n'a pas eu d'effet sur sa progression. La période fut marquée par un début de diversification et d'extension des opérations de mécanisation aux cultures vivrières. De 1994 à 2003, la traction animale a progressé à un rythme soutenu. Elle est devenue une composante essentielle des stratégies paysannes de part sa multifonctionnalité : facteur de production, et source de revenus et d'épargne $(3,6)$. Aujourd'hui, malgré un taux d'équipement de 25 p. 100,85 p. 100 des paysans ont régulièrement recours à la traction animale. On dénombre environ 55000 paires de bovins, 25000 ânes de trait, 5000 chevaux de trait, 95000 charrues, 24200 ensembles sarcleurs, 18500 corps butteurs et seulement 8500 chars à boeufs (18).

L'Etat ne s'est pas encore désengagé ; la Sodécoton assure toujours le financement et la distribution des matériels agricoles aux paysans. Les remboursements des crédits sont prélevés directement à la source lors de la commercialisation du coton. Ce système fonctionne bien, car plus de 99 p. 100 des sommes prêtées sont récupérées. Chaque année, la Sodécoton accorde 400 à 700 millions Fcfa de crédits d'équipement, soit l'équivalent de 9000 charrues (19). Elle s'approvisionne auprès des industries locales (Tropic, puis Manucycle) qui fournissent du matériel de qualité mais coûteux. Petit à petit, les artisans se sont appropriés la quasi-totalité du marché des pièces détachées à des prix défiant toute concurrence, mais souvent de qualité moindre. Ils fabriquent aussi des charrues moyennes (9 inches) et légères ( 7 inches). Bovins et ânes sont sur- tout utilisés pour le travail du sol, et l'entretien des cultures (buttage et sarclage).

\section{Province de la Tapoa au Burkina Faso}

Au Burkina Faso, la traction animale a été introduite en 1925, mais elle ne l'a été, dans la province de la Tapoa, que beaucoup plus tard. De 1975 à 1983, des programmes d'Etat mis en œuvre par les Organismes régionaux de développement (ORD) ont fait progresser la traction animale. En 1980, le pays comptait 135000 unités de matériels agricoles (charrues, multiculteurs, semoirs et charrettes) et 140000 animaux de trait. De 1983 à 1991, le rôle de l'Etat s'est renforcé dans les secteurs de l'agroéquipement par des industries locales, le Centre national d'équipement agricole (Cnea) et l'Atelier pilote de construction de matériel agricole (Apicoma), et des organismes de financement, la Caisse nationale de crédit agricole (Cnca). En 1990, les effectifs d'animaux de trait et de matériels agricoles étaient estimés respectivement à 440000 têtes et 425000 unités. Au cours des dix dernières années, l'Etat a eu la volonté de transférer au secteur privé la fabrication des matériels. Il a mis en place, avec le soutien de bailleurs de fonds, le projet de Promotion des entreprises rurales de construction métallique et des mécaniciens (Percomm) et le projet de Promotion de l'artisanat au Burkina (PAB). Parallèlement, il a conduit plusieurs programmes d'équipements : l'opération 30000 charrues de 1991, l'opération 2000 multiculteurs de 1996, le Projet d'appui à la mécanisation agricole (Pama) à partir de 1997... La traction animale a continué sa progression; en 1997, les effectifs nationaux d'animaux et de matériels agricoles étaient estimés respectivement à 650000 têtes et 630000 unités. De nombreux projets privés, missions et ONG ont également contribué au développement de la traction animale.

\section{La traction animale, élément clé des systèmes de production des zones étudiées}

Dans les zones étudiées, les conditions naturelles influent fortement sur le développement de la traction animale. En effet, la période disponible pour réaliser les opérations culturales avec les attelages est limitée. Seuls le transport et l'exhaure permettent de les utiliser toute l'année. Les animaux de trait travaillent environ 27 journées cumulées par an et par attelage, à raison de cinq heures par jour en saison des pluies au Nord-Cameroun $(3,6)$. Les systèmes d'entraide et d'échange de travail améliorent la durée d'utilisation des animaux de 50 p. 100.

Les contraintes pathologiques pour le bétail se manifestent, audessus de $800 \mathrm{~mm}$ et en dessous de $1500 \mathrm{~m}$ d'altitude, sous couvert arbustif, par le développement des trypanosomoses qui font des ravages chez les animaux sensibles (zébus et équidés). Dans les zones infestées, ne peuvent être élevés que des bovins trypanotolérants (taurins) et, dans les autres, des zébus avec un bon suivi sanitaire. C'est une des raisons de l'importance prise par la traction bovine sur les tractions équine et asine dans les villages étudiés situés dans les zones plus humides : Boaguidigou au Burkina, Keur Bakary au Sénégal, Mafa Kilda et Fignolé au Cameroun.

La combinaison des conditions naturelles avec les modes d'exploitation du milieu et les systèmes de production se traduit par des modes d'accès et d'utilisation spécifiques de la traction animale dans chaque situation étudiée (tableaux I à IV) :

- le bassin arachidier du Sénégal ; zone semi-aride, forte densité de population, systèmes de culture à base de céréales (mil, sorgho, maiis) et arachide, exploitations à plusieurs ménages possédant chacune un attelage ;

- le bassin cotonnier du Nord-Cameroun ; zone majoritairement subhumide, densité de population variable, systèmes de culture à base de céréales (maïs, sorgho), de coton et un peu d'arachide, 
exploitations généralement à un ménage utilisant pour la majorité la traction animale (propriétaire ou locataire) ;

- la province de la Tapoa au Burkina Faso ; transition entre zones semi-aride et subhumide, faible densité de population, systèmes de culture à base de céréales, un peu de coton et d'arachide, exploitations à un ou plusieurs ménages utilisant pour la majorité la traction animale (propriétaire ou locataire).

\section{Tableau I}

Villages étudiés dans les trois zones

\begin{tabular}{|c|c|c|c|}
\hline & $\begin{array}{l}\text { Bassin } \\
\text { arachidier }\end{array}$ & $\begin{array}{l}\text { Nord- } \\
\text { Cameroun }\end{array}$ & Tароа \\
\hline Villages & $\begin{array}{l}\text { Yéri Gueye } \\
\text { Keur Bakary }\end{array}$ & $\begin{array}{c}\text { Balaza Domayo, } \\
\text { Gadas, Mowo, } \\
\text { Mafa Kida, } \\
\text { Fignolé }\end{array}$ & $\begin{array}{c}\text { Botou, } \\
\text { Boaguidigou }\end{array}$ \\
\hline $\begin{array}{l}\text { Densité population } \\
(\text { hab./km²) }\end{array}$ & 50-150 & 20-100 & $10-30$ \\
\hline $\begin{array}{l}\text { Pluviométrie } \\
\text { annuelle (mm) }\end{array}$ & $400-900$ & 800-1400 & 600-900 \\
\hline
\end{tabular}

\section{Tableau II}

Caractéristiques moyennes des exploitations des villages étudiés dans les trois zones

$\begin{array}{lccc} & \begin{array}{c}\text { Bassin } \\ \text { arachidier }\end{array} & \begin{array}{c}\text { Nord- } \\ \text { Cameroun }\end{array} & \text { Tapoa } \\ \text { Chef exploitation } & & & \\ \quad \text { Age moyen (ans) } & 53 & 43 & 42 \\ \quad \text { Homme (\%) } & 100 & 90 & ? \\ \text { Personnes/actifs } & 13 / 6,5 & 5,4 / 3,1 & 10 / 5 \\ \text { Equipées en } & 96 & 35 & 65 * \\ \text { traction animale (\%) } & & & \\ \text { Superficie cultivée (ha) } & 9 & 2,2 & 4,4 \\ \text { Assolement } & & & \\ \quad \text { Coton (\%) } & 0 & 30 & 15 \\ \text { Céréales (\%) } & 55 & 55 & 75 \\ \quad \text { Arachide (\%) } & 43 & 12 & 5 \\ \text { Elevage } & & & \\ \quad \text { Nb. bovins élevage } & 1 & 1 & 8 \\ \quad \text { Nb. petits ruminants } & 10 & 4,1 & 19 \\ \text { Exploitation (Fcfa) } & & & \\ \quad \text { Marge brute PV } & - & 291000 & 552000 \\ \text { VM ** activités } & - & 430000 & -\end{array}$

* Ce taux était de 15 \% pour l'ensemble de la Tapoa en 1993 (Ensa, 1993), mais environ la moitié des équipements aratoires de Botou et Boaguidigou ont été acquis entre 1998 et 2001

** VM : valeur monétaire des produits des différentes activités (agriculture, élevage, autres) au prix du marché

Sources : Djimtoloum, 2000, Esat/Cnearc ; Havard et Abakar, 2002, Irad/Prasac ; Ilboudo, 2001, IDR ; Maganga-Mouity, 2001, Encr

\section{Utilisation de la traction animale généralisée dans le bassin arachidier}

Dans le bassin arachidier, les concessions (unités de résidence) regroupent une ou plusieurs exploitations agricoles, elles-mêmes pouvant être constituées de plusieurs ménages. Ceci explique une superficie cultivée variant entre 2 et 17 ha, dont 40 p. 100 varient entre 5 et 8 ha. La polygamie dans 70 p. 100 des exploitations explique le nombre élevé de personnes (8). « Le centre de décision est localisé au niveau du chef de concession : il est propriétaire du matériel agricole et des animaux de trait, décide de la distribution des terres dans le ménage, du mode de travail dans l'exploitation et des investissements dans l'agriculture » (4).

Les jachères ont disparu et les espaces pastoraux ont diminué. Ainsi, 4 p. 100 des exploitations à Keur Bakary, principalement

\section{Tableau III}

Modes d'accès à la traction animale des exploitations agricoles des villages étudiés dans les trois zones (en pourcentage d'exploitation)

\begin{tabular}{lccc} 
& $\begin{array}{c}\text { Bassin } \\
\text { arachidier }\end{array}$ & $\begin{array}{c}\text { Nord- } \\
\text { Cameroun }\end{array}$ & Tapoa \\
\cline { 2 - 3 } Sans matériel & & & \\
$\quad$ Travaux manuels & 0 & 8 & 22 \\
$\quad$ Locataire attelage & 4 & 56 & 10 \\
Asin, équin & 76 & 15 & 51 \\
Bovin + asin + équin & 20 & (ânes) & (ânes) \\
& & 21 & 17
\end{tabular}

Sources : Djimtoloum, 2000, Esat/Cnearc ; Havard et Abakar, 2002, Irad/Prasac ; Ilboudo, 2001, IDR ; Maganga-Mouity, 2001, Encr

\section{Tableau IV}

Types d'attelages et de matériels agricoles dans les exploitations agricoles des villages étudiés dans les trois zones

\begin{tabular}{|c|c|c|c|}
\hline $\begin{array}{l}\text { Nb. attelage, matériel } \\
\text { par exploitation }\end{array}$ & $\begin{array}{c}\text { Bassin } \\
\text { arachidier * }\end{array}$ & $\begin{array}{l}\text { Nord- } \\
\text { Cameroun }\end{array}$ & Tapoa \\
\hline \multicolumn{4}{|l|}{ Animaux de trait } \\
\hline Bœufs & 0,6 & 0,4 & 0,4 \\
\hline Anes & 0,5 & 0,2 & 0,5 \\
\hline Chevaux & 1,7 & 0 & 0 \\
\hline \multicolumn{4}{|l|}{ Equipements } \\
\hline Charrues & 0 & 0,45 & 0,8 \\
\hline Semoirs & 1,4 & 0 & 0 \\
\hline Houes, sarcleurs & 1,7 & 0,10 & 0,15 \\
\hline Souleveuse arachide & 1,2 & & 0 \\
\hline Butteurs & 0 & 0,10 & 0,2 \\
\hline Charrettes & 0,6 & $0,02 * *$ & 0,3 \\
\hline
\end{tabular}

* Chiffres identiques à ceux de 1985 (Havard, 1987, Isra)

** Le transport est surtout effectué par des pousses : 0,15 par exploitation Sources : Djimtoloum, 2000, Esat/Cnearc ; Havard et Abakar, 2002, Irad/Prasac ; Ilboudo, 2001, IDR ; Maganga-Mouity, 2001, Encr 
des migrants, et 11 p. 100 à Yéri Gueye, originaires du village, n'ont pas de terres en propriété. Les locations gratuites et payantes (15 $000 \mathrm{Fcfa} /$ ha pour un an à Keur Bakary) touchent pratiquement la moitié des exploitations, mais la législation foncière ne favorise pas cette pratique, car après quatre ans de location, le propriétaire de la terre peut en perdre l'usufruit.

L'assolement est à base d'arachide et de céréales en cultures pures. Le mil (52 p. 100 de l'assolement) domine à Yéri Gueye, devant l'arachide (36 p. 100), le sorgho (7 p. 100) et le niébé (5 p. 100), tandis qu'à Keur Bakary, l'arachide représente 47 p. 100 de l'assolement, devant le mil (45 p. 100), le maïs (5 p. 100) et le sorgho (3 p. 100). La culture des céréales vise en priorité la sécurité alimentaire de la famille et celle de l'arachide la production de revenu. Les fanes de légumineuses sont aussi utilisées pour l'alimentation des animaux de trait. Environ 50 p. 100 des exploitations possèdent des caprins et 56 p. 100 des ovins ; ces animaux appartiennent surtout aux femmes. Les effectifs sont plus importants à Yéri Gueye ( 9 ovins et 7 caprins par exploitation) qu'à Keur Bakary (3 ovins et 3 caprins). Les pratiques de confiage sont importantes pour tous les animaux, car elles intéressent autant ceux qui les confient que ceux qui les prennent en confiage (ceux qui les confient bénéficient d'une partie des récoltes sans avoir à faire face aux contraintes d'alimentation croissantes ; ceux qui les prennent en confiage assurent l'alimentation et les soins aux animaux; en retour, ils bénéficient d'une partie des produits et du travail). Plus de 90 p. 100 des exploitations agricoles possèdent des animaux de trait (équins, bovins, asins) et une houe (Sine ou occidentale). Mais avec les pratiques de location de matériels agricoles et de confiage d'animaux de trait, l'ensemble des exploitations a recours à la traction animale pour les travaux agricoles. Seuls, les étalons, environ la moitié des effectifs équins, et les ânes sont utilisés avec les charrettes présentes dans 50 p. 100 des exploitations.

\section{L'adoption de la traction animale en progression dans la Tapoa}

L'exploitation agricole composée d'un ou de plusieurs ménages est sous l'autorité du chef de famille, en général la personne la plus âgée. A Boaguidigou, les exploitations à un ménage sont plus nombreuses, ce qui explique qu'un chef d'exploitation y est plus jeune (39 ans) qu'à Botou (44 ans), et aussi que le nombre de personnes (9) et d'actifs $(4,2)$ par exploitation y est plus faible qu'à Botou (13 personnes et 5,4 actifs). Le chef d'exploitation est chargé de l'organisation et de la planification des activités au cours de la campagne : distribution des tâches, utilisation du matériel de culture attelée. A côté du champ commun de l'exploitation cultivé en céréales, chaque membre (femme ou homme) âgé d'au moins 8 ans peut disposer de champs individuels dont la production lui incombe. Seuls les hommes ont le droit d'usage sur la terre qu'ils exploitent. Aujourd'hui, la terre constitue une véritable contrainte, car les possibilités d'extension sont limitées et les terres cultivées sont appauvries. L'élevage est surtout constitué de petits ruminants dont chaque individu appartient à un seul membre de la famille. Traditionnellement, la fumure organique était rassemblée et brûlée ; aujourd'hui, elle est très appréciée (50 p. 100 l'utilisent) et certains producteurs commencent ou souhaitent commencer leur équipement par la charrette, pour en faciliter le transport.

A Botou, environ la moitié des exploitations ont au moins un animal de trait (13), essentiellement des ânes, intéressants pour le transport avec la charrette. Avec les prêts d'attelages et les entraides, 64 p. 100 des producteurs ont labouré les champs de céréales et l'arachide. La faible pluviosité, en avril, mai et juin, amène les producteurs à semer une bonne partie de leurs champs sans labour, pour ne pas rater le début de campagne. La superficie moyenne cultivée par exploitation est de 3,7 ha : 90 p. 100 de céréales (petit mil, sorgho blanc et un peu de maïs), 8 p. 100 d'arachide et 2 p. 100 de cultures diverses (tabac, indigo, coton, cultures maraîchères). Seules 13 p. 100 des exploitations utilisent des engrais chimiques, mais 66 p. 100 utilisent la fumure organique, principalement dans les champs de case et un peu dans les champs de brousse, transportée à l'aide des vélos et de paniers. Une exploitation agricole moyenne possède neuf bovins et 22 petits ruminants. Les charges variables de culture sont faibles (5 000 Fcfa), car l'utilisation des intrants chimiques et la main d'œuvre salariée est limitée.

A Boaguidigou, la traction animale existe dans 85 p. 100 des exploitations agricoles. Elle est utilisée pour le labour du coton, des céréales et de l'arachide. Les jeunes montrent un réel intérêt pour la traction animale en achetant les équipements au moment, voire même avant de créer leur propre exploitation. La superficie moyenne cultivée par exploitation est de 5,1 ha: 63 p. 100 de céréales (petit mil, sorgho blanc et maiis), 35 p. 100 de coton et 2 p. 100 de cultures diverses (arachide, tabac, indigo, coton, cultures maraîchères). Grâce à la Sofitex, 81 p. 100 des exploitations utilisent les engrais chimiques sur coton et céréales. Cependant, sur coton, les quantités sont faibles $(75 \mathrm{~kg} / \mathrm{ha})$ et nettement inférieures à celles recommandées (200 kg/ha). Environ 40 p. 100 utilisent la fumure organique sur les champs de case. Une exploitation agricole moyenne possède sept bovins et 16 petits ruminants. Les charges variables de culture sont élevées (109 $000 \mathrm{Fcfa})$ à cause de la culture du coton qui augmente l'utilisation d'engrais chimique et le recours à la main d'œuvre salariée.

\section{Le processus d'équipement des exploitations agricoles poursuivi au Nord-Cameroun}

Au Nord-Cameroun, l'exploitation agricole moyenne est atomisée car les garçons et les filles se marient jeunes : 37 p. 100 des chefs d'exploitation ont moins de 35 ans (11). L'âge moyen des chefs d'exploitation est de 43 ans et 10 p. 100 d'entre eux sont des femmes, généralement des veuves et des divorcées. La superficie cultivée est réduite et stable d'une année à l'autre : 80 p. 100 cultivent moins de 3 ha et 30 p. 100 moins de 1 ha. L'élevage (1 bovin, 4 petits ruminants, 0,6 porc) et la traction animale $(0,4$ bovin de trait, 0,45 charrue) progressent lentement. Un tiers des chefs d'exploitation sont propriétaires d'attelages (paires de bœufs ou d'ânes), 56 p. 100 locataires et 8 p. 100 opèrent entièrement manuellement. Dans les terroirs de la province de l'Extrême-Nord, le taux d'équipement des exploitations est voisin de 45 p. 100 et la traction asine domine la traction bovine. Dans ceux du Nord, le taux d'équipement est de 25 p. 100, en traction bovine essentiellement. Les taux d'équipement en traction animale observés dans la région, la prédominance de différentes formes d'accès à ces équipements (propriétaires et locataires), malgré l'insuffisante valorisation de la technique (18), témoignent d'une volonté d'adaptation de la technique par les agriculteurs, chacun selon sa situation.

La productivité du travail demeure faible ( 0,7 à 0,8 ha/actif), mais les échanges de travail entre exploitations (traction animale, main d'œuvre salariée, entraide) sont très répandus. La saison agricole étant relativement courte (mai à décembre), souvent les membres de l'exploitation ont des activités extra-agricoles pendant la saison sèche. Les rendements observés sont relativement faibles : $950 \mathrm{~kg}$ / ha de coton, $2100 \mathrm{~kg} / \mathrm{ha}$ de maïs, $850 \mathrm{~kg} / \mathrm{ha}$ de sorgho, $470 \mathrm{~kg} / \mathrm{ha}$ de muskwari et $1800 \mathrm{~kg} / \mathrm{ha}$ d'arachide coque. La fumure minérale est utilisée principalement sur coton $(110 \mathrm{~kg} / \mathrm{ha}$ de NPK et $25 \mathrm{~kg} /$ ha d'urée) et maïs ( $90 \mathrm{~kg} / \mathrm{ha}$ de NPK et $80 \mathrm{~kg} / \mathrm{ha}$ d'urée). Les rendements sont plus élevés dans la province du Nord.

La valeur monétaire des productions (vente, autoconsommation et dons) et des activités est estimée entre 370000 et 450000 Fcfa par exploitation, dont 80 p. 100 environ pour les productions végétales, 5 p. 100 pour l'élevage et 15 p. 100 pour les activités extra-agricoles. Le coton représente deux tiers des revenus monétaires (1). 
Entre 1998 et 2000, 85 à 90 p. 100 des exploitations ont cultivé le coton. L'assolement moyen d'une exploitation est resté stable : 30 p. 100 de coton, 55 p. 100 de céréales (sorgho, maïs, muskwari et riz), 12 p. 100 de légumineuses (arachide et niébé) et 3 p. 100 de cultures diverses (canne à sucre, macabo, oignon, manioc, cultures légumières...). Le niébé est souvent cultivé en association avec le coton et l'arachide avec le sorgho. Le chef d'exploitation gère 85 p. 100 des superficies cultivées (céréales, coton et divers), les femmes 10 p. 100 (arachide et coton) et les autres membres de la famille environ 5 p. 100.

\section{- CONCLUSION}

Dans les situations étudiées, le contexte de développement de la traction animale évolue avec le désengagement des Etats des filières de cultures industrielles et la libéralisation du secteur agricole. Les services d'appui au développement de la traction animale, autrefois assurés par des structures de l'Etat, se réorganisent. Les artisans du fer et les commerçants en bétail prennent progressivement le relais des structures de l'Etat. En revanche, les nouveaux prestataires des services immatériels (services financiers, appui/conseil, actes vétérinaires) ont des difficultés à adapter leur offre à la demande et à dégager une rentabilité suffisante (20). Deux grandes tendances d'utilisation de la traction animale se dégagent dans les zones étudiées en réponse principalement aux contraintes du milieu.

La première, dans les zones les plus sèches, les conditions climatiques nécessitent de semer rapidement, si possible sans travail du sol, et ensuite d'assurer rapidement l'entretien des cultures, car tout retard de semis peut se traduire par une baisse de rendement importante. Les stratégies des paysans diffèrent selon les zones. Dans le bassin arachidier au Sénégal, la priorité d'équipement des paysans est le semoir, pour le semis en sec du mil et du sorgho, et celui de l'arachide sur les premières pluies, car les terres sableuses et suffisamment dessouchées permettent le passage du semoir. Dans la partie septentrionale du Nord-Cameroun, la mécanisation du semis n'ayant jamais été une priorité, le semoir est absent. Le sorgho est souvent semé sans travail du sol et le labour est pratiqué essentiellement sur le coton.

La seconde, dans les zones plus humides (Tapoa au Burkina et partie méridionale du Nord-Cameroun), la période favorable à l'implantation des cultures est plus longue, les pluies arrivant plus précocement, favorisent la levée des mauvaises herbes. Les stratégies des paysans visent la destruction des mauvaises herbes avant le semis, soit par le labour, soit par le buttage à la charrue, soit par le semis direct après traitement herbicide.

Cette étude met en évidence une diversité d'utilisation de la traction animale et des degrés variables de privatisation des services d'appui que le développement et la recherche doivent prendre en compte : ils doivent adapter leurs programmes, mais aussi leurs méthodes et pratiques à la diversité des situations rencontrées.

\section{BIBLIOGRAPHIE}

1. BALKISSOU MOUSSA, 2000. Pratiques de gestion des ressources alimentaires et monétaires dans les exploitations agricoles du NordCameroun. Cas des terroirs de Fignolé et Mowo. Mémoire Ingénieur agronome, faculté d'Agronomie et des Sciences agricoles, université de Dschang, Cameroun, 72 p.

2. BENOIT-CATTIN M. éd., 1986. Recherche et développement agricole : les unités expérimentales du Sénégal. Montpellier, France, Cirad-dsa, 500 p.

3. CUVIER L., 1999. Etude des pratiques et des stratégies paysannes de traction animale dans la zone cotonnière du Nord-Cameroun : cas du terroir de Mafa-Kilda. DESS Productions animales en régions chaudes, Cirad-emvt, Montpellier, France, 82 p. + annexes.
4. DIOUF M.N., 1997. La traction équine et asine dans le nord du bassin arachidier : situation actuelle et perspectives. Mémoire de titularisation. Bambey, Sénégal, Isra.

5. DimTOlOuM E., 2000. Etudes des pratiques et des stratégies paysannes en matière de traction animale dans le sud du bassin arachidier du Sénégal: cas du village de Keur Bakary - communauté rurale de Kaymor. Mémoire fin d'étude, Esat/Cnearc, Montpellier, France, 92 p.

6. DONGMO NGOUTSOP A.L., 1999. Pratiques et stratégies paysannes de traction animale en zone cotonnière du Nord-Cameroun : cas du terroir de Mowo. Mémoire Ingénieur agronome, département des Productions animales, faculté d'Agronomie et des Sciences agricoles, université de Dschang, Cameroun, 121 p. + annexes.

7. ENSA, 1993. Enquête nationale de statistique agricole. Ouagadougou, Burkina Faso, Ensa.

8. FALL A., 2000. Traction animale au Sénégal et dans le bassin arachidier. In : La traction animale, composante essentielle des stratégies paysannes d'Afrique de l'Ouest et centrale: quelles sont les pratiques de recherche à envisager face au désengagement des Etats, Garoua, Cameroun, 7-11 février 2000, 18 p.

9. HAVARD M., 1987. Comment évolue le niveau d'équipement en culture attelée des paysans du Sine Saloum depuis l'arrêt du Programme Agricole en 1980. Note d'information 87/7. Dakar, Sénégal, Isra, 15 p.

10. HAVARD M., FAYE A., 1988. Eléments d'analyse de la situation actuelle de la culture attelée au Sénégal: perspectives d'études et de recherches. In : Starkey P., Ndiamé F. Eds, Animal power in farming systems. Esborn, Allemagne, Gate, GTZ, p. 241-252.

11. HAVARD M., ABAKAR O., 2002. Caractéristiques et performances des exploitations agricoles des terroirs de référence du Prasac au Cameroun. Garoua, Cameroun, Irad/Prasac, 27 p.

12. HAVARD M., LE THIEC G., VALL E., 1998. Stock numbers and use of animal traction in Sub-Saharan French-speaking Africa. Agric. Mech. Asia, Afr. Latin Am., 29: 9-14.

13. ILBOUDO I., 2001. Etude socio-économique des pratiques agricoles et évaluation du passage de la culture manuelle à la culture attelée dans la Tapoa, Burkina Faso: cas des zones de Botou et Boaguidigou. Mémoire Ingénieur Développement rural, IDR, université polytechnique, Bobo-Dioulasso, Burkina Faso, 66 p.

14. LE THIEC G., HAVARD M., 1996. Les enjeux du marché des matériels agricoles pour la traction animale en Afrique de l'Ouest. Agric. Dév., 11 : 39-51

15. LHOSTE P., 1986. L'association agriculture-élevage. Evolution du système agropastoral au Siné Saloum (Sénégal). Thèse Doct. Ingénieur, INA Paris-Grignon, France, 314 p.

16. MAGANGA-MOUITY M., 2001. La traction animale, face au désengagement de l'Etat, pratiques et stratégies paysannes : cas du village de Yéri Guéye (Bassin arachidier, Sénégal). Mémoire Ingénieur, Encr, Bambey, Sénégal, 64 p.

17. SODECOTON, 1999. Rapport semestriel de mai à octobre 98 Campagne agricole 1998/99. Garoua, Cameroun, DPA / Sodécoton, 45 p. + annexes.

18. VALL E., DONGMO NGOUTSOP A.L., ABAKAR O., CUVIER L., 2002. La traction animale: une innovation technique en phase d'institutionnalisation encore fragile. In : Jamin J.Y., Seiny Boukar L. éds, Savanes africaines : des espaces en mutation, des acteurs face à de nouveaux défis, Garoua, Cameroun. N'Djamena, Tchad, Prasac.

19. VALL E., DONGMO NGOUTSOP A.L., ABAKAR O., MEYER C., 2002. La traction animale dans le nouveau contexte des savanes cotonnières du Tchad, du Cameroun et de la République centrafricaine. I. Diffusion de la traction animale et sa place dans les exploitations. Revue Elev. Méd. vét. Pays trop., 55 : 117-128.

20. VALL E., LHOSTE P., ABAKAR O., DONGMO NGOUTSOP A.L., 2003. La traction animale dans le contexte en mutation de I'Afrique subsaharienne: enjeux de développement et de recherche. Cah. Agric., $12: 219-226$.

21. VIDEAULT S., 2001. Analyse des besoins et des stratégies de financement de la traction animale des exploitations agro-pastorales de la province de la Tapoa, Burkina Faso - Pays Gourmanché. Mémoire fin Etudes, Istom, Paris, France, 119 p. 


\section{Summary}

Havard M., Traoré A., Njoya A., Fall A. Draft Animal Power and Its Sociotechnical Environment in Burkina Faso, Cameroon and Senegal

Draft animal power is being developed in Burkina Faso, Cameroon and Senegal in an evolving environment that is characterized by government disengagement from cash crops, and general liberalization of the agricultural sector. In Senegal, the level of use of draft animal equipment is stable and has been higher than $95 \%$ for the past 25 years in the groundnut basin. In North Cameroon, although its level is below 35\%, the use of draft animal power has been increasing continuously as a result of support activities by the Cotton Development Corporation. In Burkina Faso, the rate of adoption of draft animal power goes up and down in the Tapoa area depending on the existence of short-term agricultural support programs and projects. Privatization of draft animal power support services, which had been taken care of by the State, has been achieved in Senegal and is under way in the other two countries. This privatization shows that iron craftspeople and traders handle as best they can supply and repairs of equipment, and animal care. However, the new service providers (financial credits, support/consultancy, veterinary services) face difficulties in adapting their offers to the demands. In the driest zones, farming conditions require early planting and weeding, as any delay can lead to significantly reduced yields. Consequently, $90 \%$ of farms in the Senegalese groundnut basin have planting and weeding implements; in the northern part of Cameroon's cotton belt, planting implements are absent and cereals are often planted without tillage. In the more humid zones (Tapoa area in Burkina Faso and the southern part of North Cameroon), the propitious planting period lasts longer. The early rains produce weeds that must be buried by tillage using draft animal power before planting. The diversity in the use of draft animal power and the varying degrees of privatization of agricultural support services require development agencies and research institutions to adapt their programs to the changing environment.

Keywords: Animal Power - Draft Animal cultivation Privatization - Equipment - Maintenance - Burkina Faso Cameroon - Senegal.

\section{Resumen}

Havard M., Traoré A., Njoya A., Fall A. La tracción animal y el ambiente que la rodea en Burkina Faso, Camerún y Senegal

En Burkina Faso, Camerún y Senegal, la tracción animal continúa su progreso en un contexto de desentendimiento de los estados de las filiares de cultivo industrial y de la liberalización del sector agrícola. Desde hace 25 años, el nivel de equipo de las explotaciones agrícolas es estable y superior a $95 \%$ en la cuenca de cacahuetes senegalesa. Es inferior a 35\% en Camerún del norte, con un crecimiento regular gracias a la acción de la sociedad algodonera de Camerún del norte; mientras que en Tapoa, Burkina Faso, progresa por periodos, en función de los programas orientados de apoyo a la agricultura. La privatización de los servicios de apoyo a la tracción animal, asegurados por estructuras estatales, es efectiva en Senegal y está en curso en los otros dos casos. Esta privatización muestra que el abastecimiento y el mantenimiento de los animales y de los equipos agrícolas es asegurado mal que bien por los artesanos del hierro y los comerciantes. En revancha, los nuevos prestatarios de servicios no materiales (servicios financieros, apoyo/consejo, actos veterinarios) tienen dificultades para adaptar la oferta a la demanda. En las zonas más secas, las condiciones necesitan un cultivo rápido y un mantenimiento precoz de los cultivos. Esto explica la presencia de semilleros y de azadas en la cuenca de cacahuetes de Senegal, el cultivo manual sin arado del suelo sobre los cereales en el norte de Camerún. En las zonas más húmedas (Tapoa en Burkina y la parte meridional del norte de Camerún), el periodo favorable para la implantación de cultivos es más largo. Las Iluvias precoces favorecen la aparición de la vegetación que se encuentra bajo tierra antes de los cultivos mediante arado con bueyes. Esta diversidad de utilización y del medio que rodea a la tracción animal pide que el desarrollo y la investigación adapten sus programas a los distintos contextos.

Palabras clave: Energía animal - Cultivo a tracción Privatización - Equipo - Mantenimiento - Burkina Faso Camerún - Senegal. 